\title{
A SIMPLIFIED INSTRUMENT FOR RECORDING STRONG MOTION EARTHQUAKES
}

\author{
By W. K. Cloud and D. E. Hudson
}

\begin{abstract}
A strong-motion earthquake recorder for the direct measurement of one point on the response spectrum curve is described, and results obtained with the instrument under field conditions are compared with those obtained by a standard spectrum analysis of accelerograph records. The device has the advantages of low initial cost and of low maintenance expense, and can thus be installed in relatively large numbers. A network of such instruments located at points having various local geological conditions is proposed as a supplement to the U. S. Coast and Geodetic Survey strong-motion seismograph system.
\end{abstract}

The ideal instrument for providing the strong-motion earthquake information desired by the structural engineer is a device that will measure the true ground acceleration versus time. This has been accomplished with notable success by the U. S. Coast and Geodetic Survey accelerograph, which for the past 25 years has been producing the fundamental data on which the recent developments of earthquake-resistant design have been based. Such accelerographs should be located within 20-50 miles of the epicenters of large earthquakes. A large number of accelerographs would thus be needed to adequately cover the areas of the world in which such earthquakes might occur. Even a superficial coverage of the major seismic areas with recording accelerographs would involve a prohibitively high expense. There has always been a great interest in the development of simpler devices which could be widely distributed, even though the information obtained might not be as complete as that from a true accelerograph.

The major simplification usually introduced into such devices is the elimination of the time-recording feature. The designer can thus dispense with the need for a power supply which also simplifies installation and maintenance. The basic principle of such instruments is the measurement of a maximum response parameter of a typical physical system whose dynamic properties can be theoretically related to the structures of ultimate interest to the engineer.

One of the first systematic attempts to produce an instrument of this kind was made in 1913 by Galitzin, who suggested that a series of rectangular blocks of various proportions could be calibrated in terms of the blocks that would be overturned by a given acceleration (1). ${ }^{1}$ This work was later extended and additional studies were made by Kirkpatrick (2). The falling-pin gages still being used as an indication of the severity of ground motion caused by blasts are modern adaptations of this idea (3).

The first notable attempt to produce a truly quantitative instrument along the above lines was made in 1926 by Suyehiro $(4,5)$. Instead of falling blocks or columns, he took as his elementary physical system a series of linear spring-massdashpot elements of known periods and damping. This Suyehiro "Seismic Vibra-

Manuscript received for publication October 24, 1960, and, as revised, January 13, 1961.

1 Numbers in parentheses refer to the list of references at the end of this paper. 
tion Analyzer" consisted of a series of cantilever beams of various periods adjusted to the same value of damping. The motions of each of these beams caused by an earthquake were recorded on a rotating drum from which the maximum responses could be determined. This instrument is thus the direct prototype for what is now usually called a "reed gage", widely used for shock measurements for various military applications.

If the maximum readings of Suyehiro's instrument are plotted versus period, the result will be what is now called a damped response spectrum curve. The instrument can thus be thought of as a direct way of measuring the earthquake response spectrum. It is perhaps unfortunate that at the time the Seismic Vibration Analyzer was developed the full implications of the device were not generally realized, and the advantages of the instrument were never fully exploited. An instrument operating on a similar principle was constructed in the late 1930 s by the U. S. Coast and Geodetic Survey, but in this case also the necessary details for an extensive application were never worked out (6).

\section{Design Characteristics for a Simplified Instrument}

In the early 1950s, the attention of the Earthquake Engineering Research Institute was directed to the necessity for increased strong-motion instrumental coverage. The information already gained by the response spectrum analysis of Pacific Coast strong-motion accelerograms was at that time sufficient to indicate design parameters suitable for a simplified device, and it was concluded that the pattern of the damped response curves was well enough known so that a single spectrum point would serve as a useful measure of the spectrum intensity level. After a study of the response spectrum curves for all of the recorded strong-motion earthquakes, it was decided that the single spectrum point that would give the maximum information would be a period of 0.75 seconds and $10 \%$ of critical damping. This was based on the fact that at periods above this value the velocity response spectrum curves tended to become constant independent of period, whereas at lower periods the response dropped off markedly. The $10 \%$ damping was sufficient to insure a relatively smoothly varying spectrum curve without local peaks, and yet was not so high that the response was reduced to a value difficult to measure.

The suitability of this particular point was checked by studies made of the unusually complete strong-motion data from the San Francisco Earthquake of March 22,1957 , which further confirmed the usefulness of these particular design parameters (7).

\section{The U. S. Coast and Geodetic Survey Sersmoscope}

Based on the above ideas, the U. S. Coast and Geodetic Survey designed and constructed an experimental model of a single-period response spectrum type strongmotion recorder. This device served as the prototype for the development of a standard model for field use, which was produced by the California Institute of Technology and the Wilmot Engraving and Instrument Company, under a grant from the National Science Foundation. It is this model, shown in fig. 1, and commonly referred to as a "seismoscope", which is described in the following sections.

The seismoscope consists of a free conical pendulum which can move in any hori- 
zontal direction. The wire flexure pivot support point of the pendulum moves with the ground, and the resulting angular deflections relative to the instrument frame are recorded by a scriber on a smoked spherical watch glass. Eddy current damping

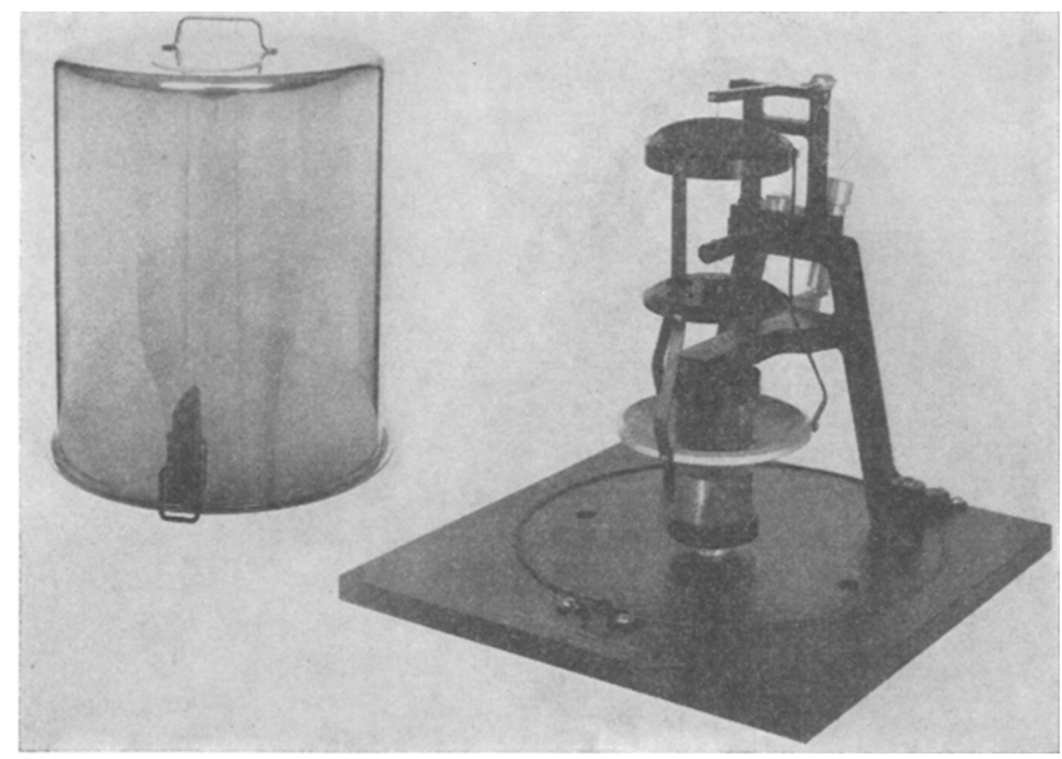

FIG. 1. Photograph of the seismoscope.
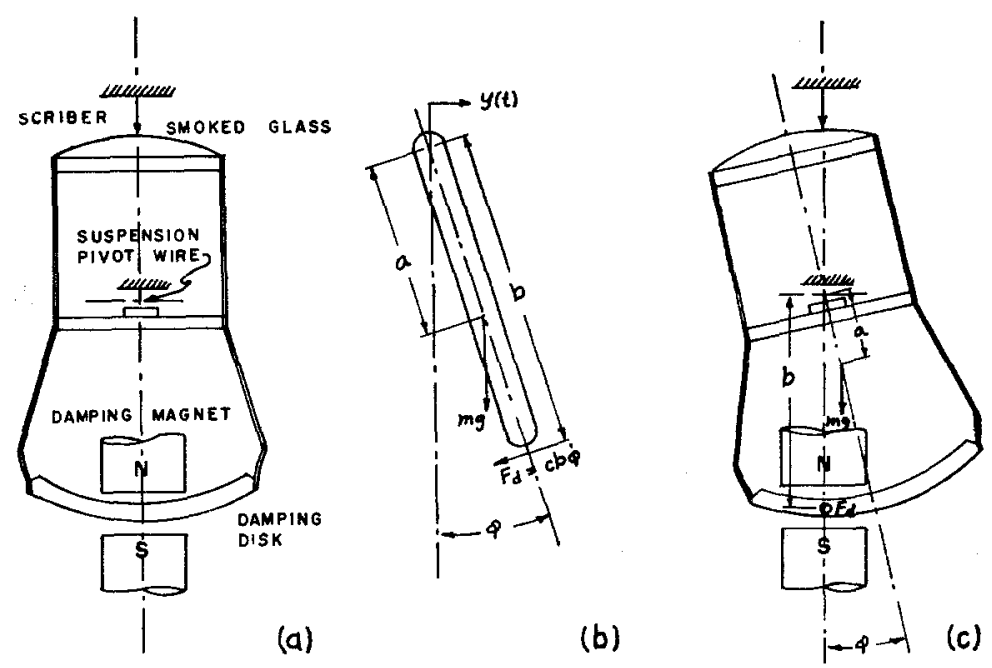

FIG. 2. Schematic diagram of the seismoscope.

is provided by an aluminum disk in the form of a segment of a spherical shell, which moves between the poles of a permanent magnet system. This aluminum segment is a principal contributor to the moment of inertia of the compound pendulum. Since the motion in a horizontal plane is traced out as a permanent record, the sequence 
of events can be followed even though no time-recording is employed. In this way much more information than would be obtained from an indication of maximum displacements alone can be secured by a very simple means.

Complete drawings of the instrument, as well as many additional details on the design and construction of the device, will be found in a special report (8).

Referring to the diagram of fig. 2(b), the angular displacement of the pendulum, assuming motion in one plane, is:

$$
\ddot{\varphi}+\frac{c b^{2}}{I_{0}} \dot{\varphi}+\frac{m g a}{I_{0}} \varphi=-\frac{m a}{I_{0}} \ddot{y}(t)
$$

where: $m=$ total mass of pendulum

$a=$ distance from center of rotation to center of mass

$b=$ distance from center of rotation to line of action of damping force

$I_{0}=$ moment of inertia of pendulum about a transverse axis through the center of rotation

$g=$ acceleration of gravity

$c=$ viscous damping coefficient: damping force $=c b$

$\ddot{y}(t)=$ horizontal acceleration of support point

The solution of this equation is:

$$
\varphi=\frac{2 \pi}{g T \sqrt{1-n^{2}}} \int_{0}^{t} \ddot{y}(\tau) e^{-2 \pi n / T(t \rightarrow \tau)} \sin \frac{2 \pi}{T} \sqrt{1-n^{2}}(t-\tau) d \tau
$$

where: $T=2 \pi \sqrt{\frac{I_{0}}{m g a}}=$ undamped natural period of the pendulum

$$
n=\frac{c}{C_{c}}=\frac{c b^{2}}{2 \sqrt{m g a I_{0}}}: C_{c}=\text { damping coefficient for critical damping }
$$

For the small damping $(n=0.1)$ of this particular instrument, the solution becomes:

$$
\varphi=\frac{2 \pi}{g T} \int_{0}^{t} \ddot{y}(\tau) e^{-2 \pi n / T(t-\tau)} \sin \frac{2 \pi}{T}(t-\tau) d \tau
$$

By definition, the maximum relative velocity response spectrum is given by $(9,10)$ :

$$
S_{v}=\left[\int_{0}^{t} \ddot{y}(\tau) e^{-2 \pi n / T(t-\tau)} \sin \frac{2 \pi}{T}(t-\tau) d \tau\right]_{\max }
$$

We thus have finally:

$$
\varphi_{\max }=\frac{2 \pi}{g T} S_{v}
$$


and the maximum angle of the pendulum measures directly the response spectrum value.

The dimensions of the instrument are selected so that with a standard $2 \frac{1}{2}^{\prime \prime}$ watch glass recording plate a full scale deflection represents a spectrum value $S_{v} \approx 2$ $\mathrm{ft} /$ sec.

One possible difficulty which might be expected with the instrument in its present form may be seen by referring to fig. 2(c). Suppose that while the pendulum is deflected through a large angle in one direction, a large motion should simultaneously occur in the perpendicular direction. The damping force associated with this perpendicular motion would exert a torque about the suspension wire which might excite torsional oscillations of the pendulum. If a significant amount of energy were to go into this torsional mode, the amplitude of the measured motions might be appreciably reduced. A complete analysis of this problem would be expected to be complicated, because at the large angles at which the effect would be most important non-linear effects might also be significant. An approximate analysis of the order of magnitude of the torsional moment can, however, be easily made. The damping torque causing torsional motion is:

$$
T_{D}=c b^{2} \dot{\varphi} \sin \varphi
$$

whereas the gravity restoring torque is:

$$
T_{G}=m g a \sin \varphi
$$

Putting in the instrument constant $n=0.10=c b^{2} / 2 \sqrt{m g a} \bar{I}_{0}$ and noting that $\dot{\varphi}_{\max }=\varphi_{\max } \sqrt{(m g a) / I_{0}}$, we obtain

$$
\frac{T_{D}}{T_{G}} \approx 0.2 \varphi_{\max }
$$

The maximum possible angle through which the pendulum can swing is somewhat less than $30^{\circ}$, so in the worst case:

$$
\frac{T_{D}}{T_{G}} \approx 0.1
$$

and the maximum possible damping torque is of the order of one-tenth of the gravity restoring torque. The magnitudes of the motions caused by these torques are directly proportional to the respective natural periods. Since the natural period of the torsional mode is of the same order of magnitude as that of the vertical pendulum mode, we may conclude that the torsional motions would be expected to be small compared with the vertical motions. This general conclusion has been verified by shaking table tests as well as by field tests of the instrument.

The effects of the above coupled motions could be further reduced or eliminated by certain design changes. If the damping disk were fixed and the magnet were 
attached to the moving pendulum the damping torque would be practically eliminated. A disadvantage of this arrangement would be the possibility of pendulum deflection by external objects. If the glass recording plate were fixed and the stylus were attached to the moving pendulum so that it would scribe on the lower face of the plate, the torsional motions in any event would not appear on the record. Tests have shown that these refinements, which would require compromises in the design at other points, are not necessary for the present application.

Another source of error in the instrument which should be investigated is the possibility that vertical accelerations might alter the effective period of the pendulum, or in extreme cases might even lead to instability. It is well known that ground motions at right angles to the direction of motion of a pendulum-type seismograph may induce instabilities at certain critical frequencies (12). In the presence of appreciable damping, it is only the first order instability occurring at $\frac{1}{2}$ the pendulum period that is likely to be excited by any probable ground motion. In the worst possible case, it would require a steady state sinusoidal vertical acceleration of approximately $0.3 \mathrm{~g}$ at exactly $\frac{1}{2}$ of the pendulum period to approach such an unstable state. Strong-motion accelerograms of past earthquakes show that the vertical accelerations are of a very complex shape, and that they do not in general have dominant periods persisting for even 2 or 3 cycles. It would seem that the period modifications caused by such transient vertical accelerations would be in practice quite minor. A small lengthening of the pendulum period would not alter the response appreciably in any event, since the damped response spectrum curves are usually quite flat above the 0.75 second period. Field tests confirm the conclusion that the vertical accelerations are ordinarily not of concern.

\section{Damping Tests of the Pendulum}

The natural period of the pendulum is fixed by the design of the device and no significant changes are to be expected after initial adjustment and check. The damping is, however, not only adjustable, but is subject to several variable factors and hence must be occasionally checked. A standard procedure has been worked out for this damping calibration, and numerous tests have been made to ascertain the kind of control on the variables that is needed for the desired overall accuracy of the instrument $(8,11)$.

Damping forces come not only from the damping magnet assembly, but also from the friction force between the scriber and the watch glass. This scriber friction varies with the amplitude of the pendulum motion, and hence the damping is not a constant for various pendulum angles. It has been found that by standardizing the scriber points, the type of watch glass, and the force exerted by the scriber on the glass, the damping-amplitude curve can be repeated with an acceptable accuracy.

The damping can be conveniently measured by giving the pendulum an initial displacement, and by then releasing it with a slight push in a direction perpendicular to the free motion. In this way an elliptical spiral is produced, as shown in fig. 3 , a photograph of one of the record plates from a damping test. The fraction of critical damping can then be computed from the amplitude ratios of successive 


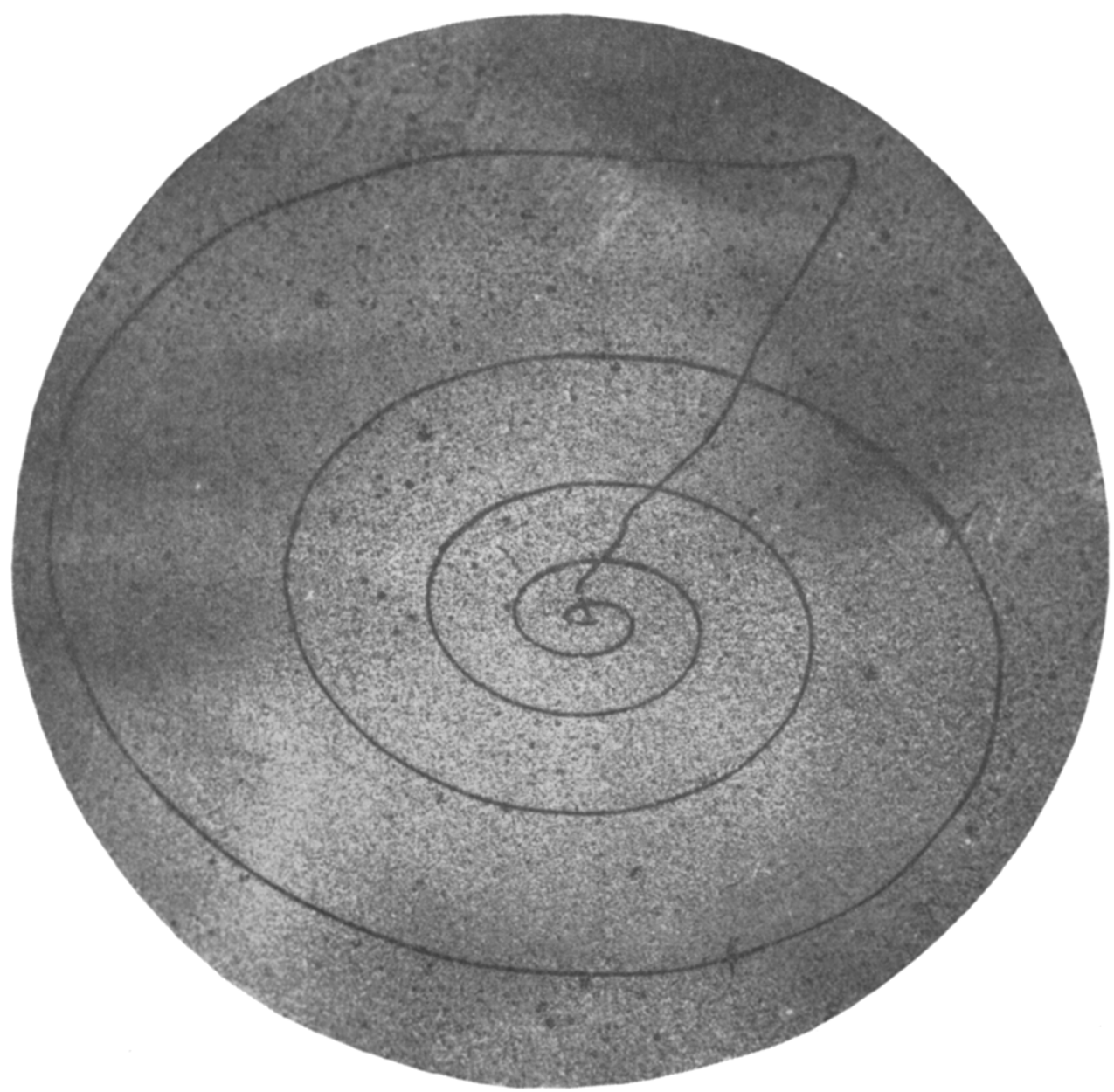

FiG. 3. Photograph of seismoscope record plate of damping test.

cycles of free vibration by the relationship:

$$
n=\frac{1}{\pi} \log _{e}\left(\frac{A_{n}}{A_{n}+1}\right)
$$

From one record plate, the damping can be calculated for a number of displacements, and plotted as in fig. 4 , which shows a typical scatter of results. By adjusting the spacing of the damping magnets, the whole curve can be moved up or down to give the desired value. As a means of standardization, field adjustments are made so that the damping has the value of $10 \%$ of critical at a deflection of $9 \pm 1 \mathrm{~mm}$ on the plate.

Since it is not to be expected that the standard damping value of $10 \%$ will be attained at the displacement corresponding to a particular earthquake, a correction 
to the final response spectrum value is made. It can be shown that if an earthquake can be approximated by series of random pulses, the relative velocity response spectrum values for the period range of the present instrument should be inversely proportional to the square root of the damping (10). For the final plotting of the data therefore, the response spectrum values are corrected according to the following expression:

$$
\left[S_{v}\right]_{10 \%}=\left[S_{v}\right]_{n} \sqrt{\frac{n}{0.10}}
$$

The relationship between the angle of the pendulum and the measured deflection on the record plate can be easily established by a simple tilt test, and a standardized procedure for this measurement has been established.

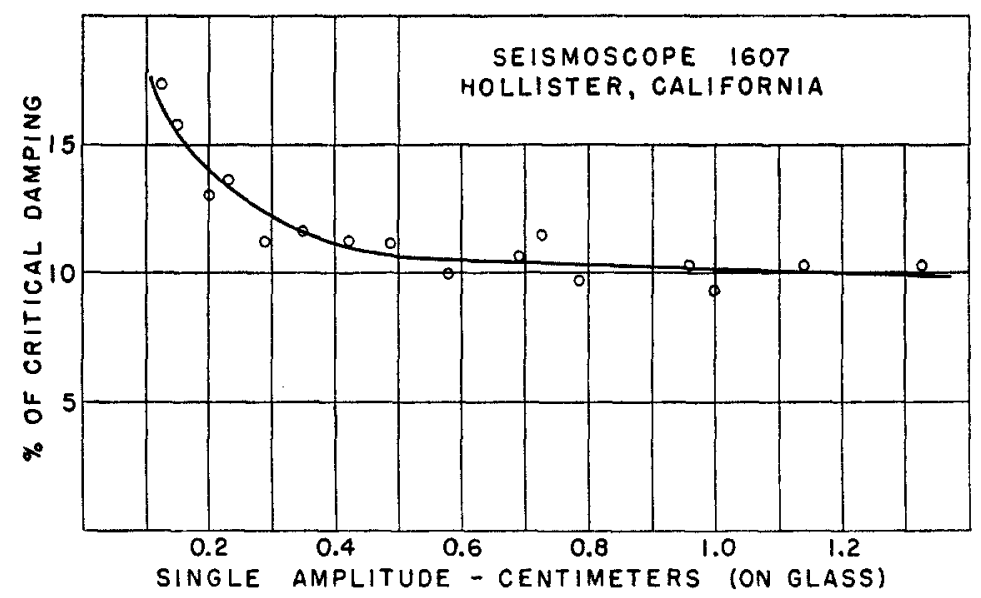

FIG. 4. Seismoscope damping versus deflection, showing typical scatter of measured points.

\section{Laboratory Tests of the Seismoscope}

During the design and development stage numerous tests were made on the instruments to check various dynamic characteristics, and to establish the duplicability of results and overall accuracy. Among these tests were two-dimensional shaking table tests with simultaneous recording of the two components of base acceleration. From these acceleration-time records, complete response spectrum determinations could be made and compared directly with the seismoscope measurements $(8,13)$.

Tests were also made in which supposedly identical instruments were subjected to the same base motions and deviations of the measured records were noted. Similarly, instruments manufactured by two different companies to the same specifications were checked together in a simultaneous test. The results of these tests indicated that with the type of adjustment to be expected in field use of the instrument, the overall accuracy is of the order of $5-10 \%$. Additional improvements could be made in the design and adjustment techniques, but it is not believed that such refinements would be justified in view of the intended use of the instrument. 


\section{Field Tests of the Seismoscope}

Acting on the favorable results of the laboratory tests, a number of seismoscopes were installed at selected stations for tests under actual field conditions. Fifty instruments were purchased by the California Institute of Technology from the Wilmot Instrument and Engraving Company with funds supplied by the National Science Foundation, and an additional forty-five seismoscopes were purchased from the Sprengnether Instrument Company by the U. S. Coast and Geodetic Survey.

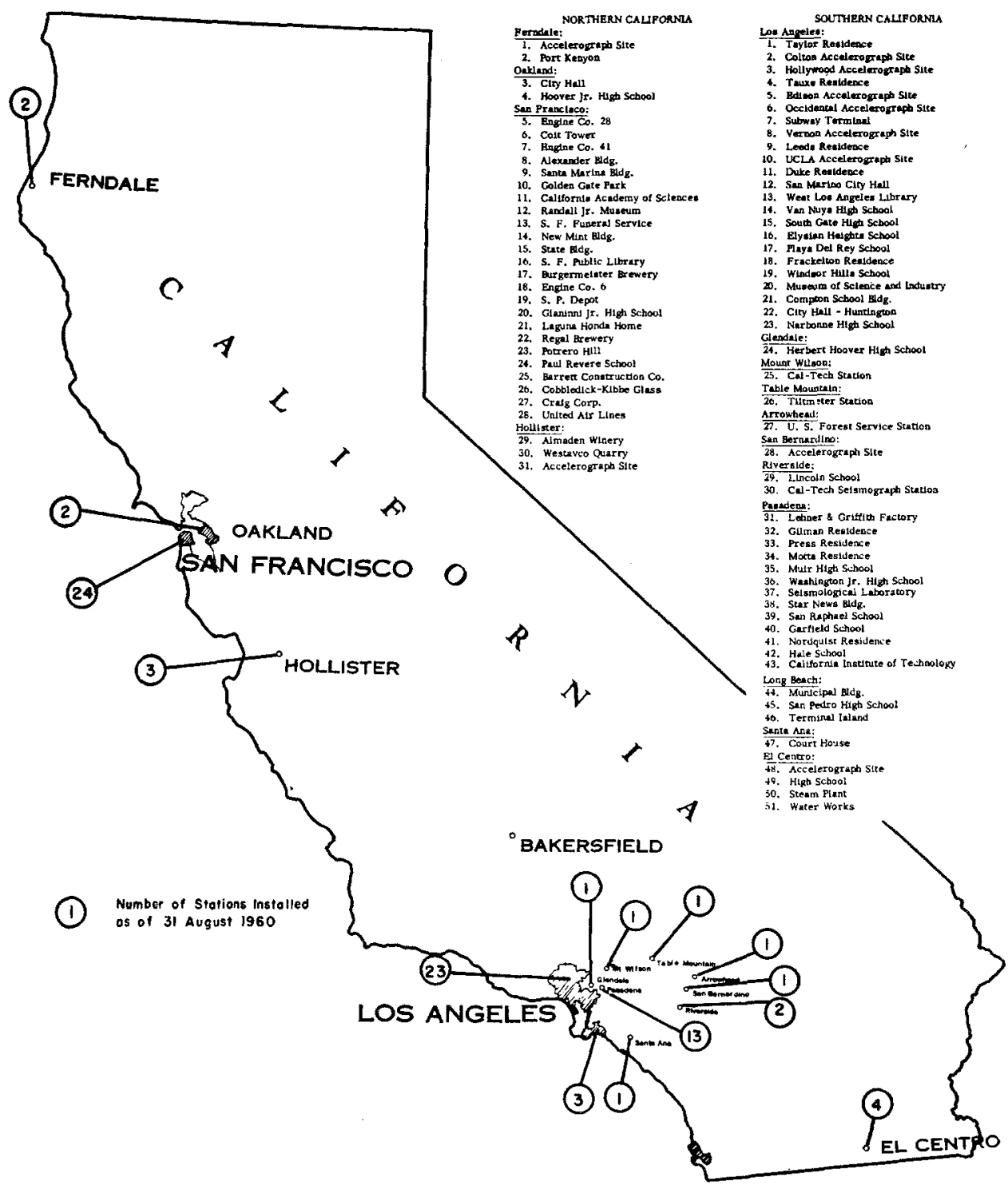

SEISMOSCOPE STATION LOCATIONS

FIG. 5. Seismoscope locations, 31 August 1960. 
HEBGEN DAM, MONTANA

AFTERSHOCK OF 27 AUGUST 1959, 1637 MST.

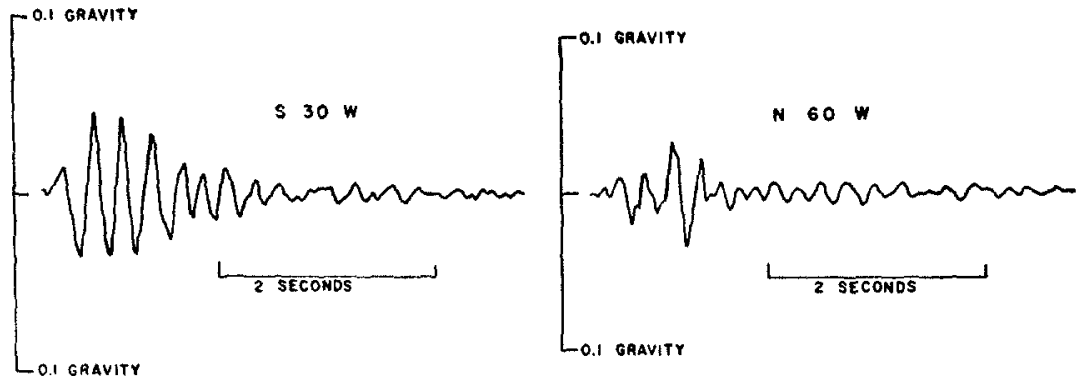

HOLLISTER, CALIFORNIA

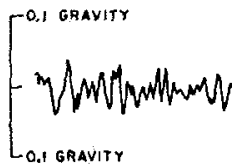

EARTHQUAKE OF 19 JAN. 1960,1926 PST.

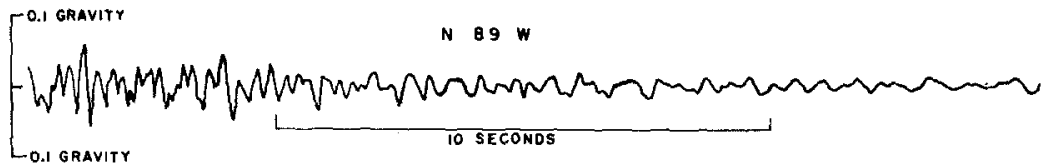

FIG. 6. Ground accelerations, Hebgen Dam, Montana aftershock of 27 August 1959, and Hollister, California, 19 January 1960.

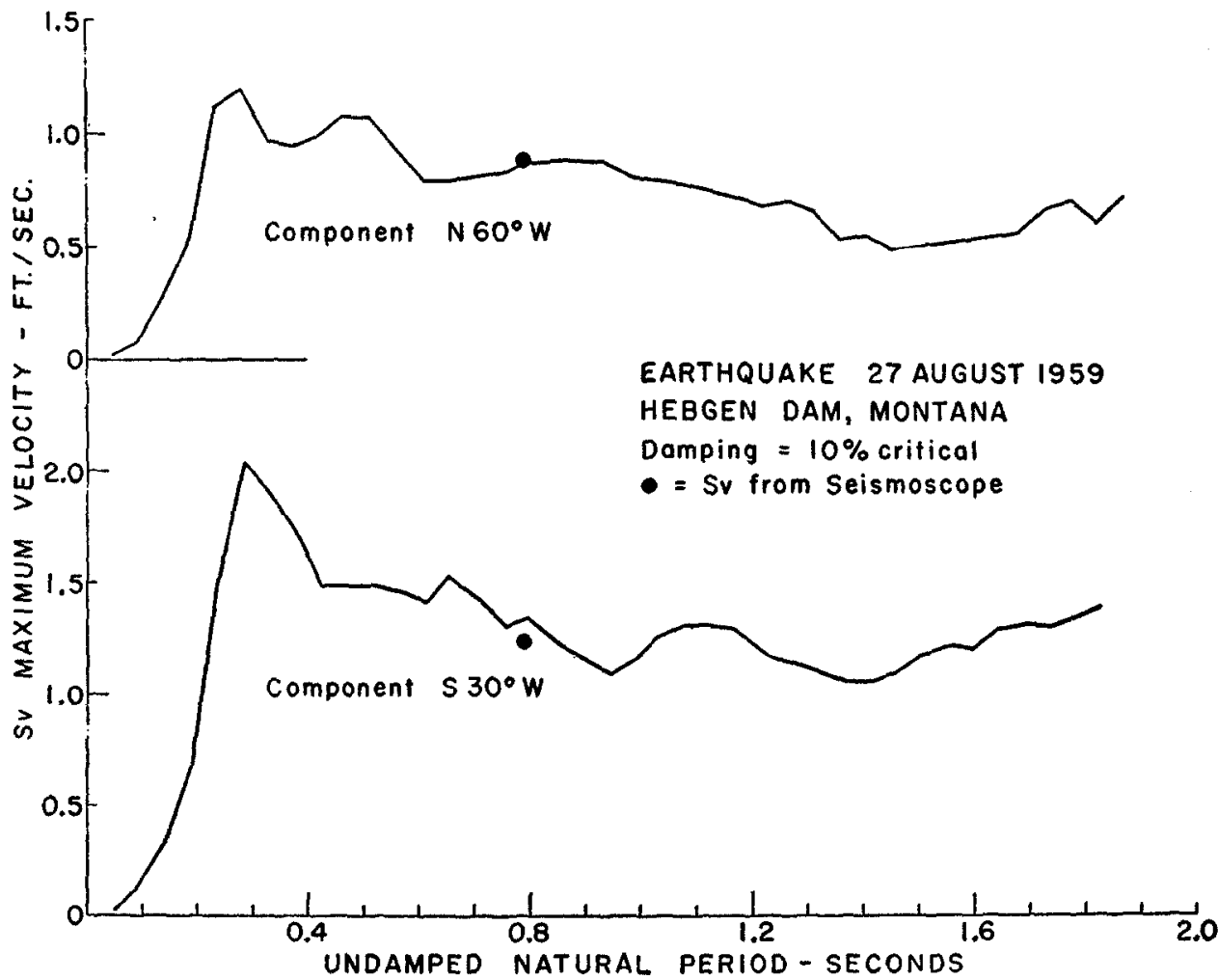

FIG. 7. Response spectrum for the Hebgen Dam earthquake of 27 August 1959. 
Responsibility for the installation and maintenance of all seismoscopes was assumed by the U. S. Coast and Geodetic Survey, since the primary purpose of the instruments was to supplement the existing U.S. Coast and Geodetic Survey network of strong-motion seismographs.

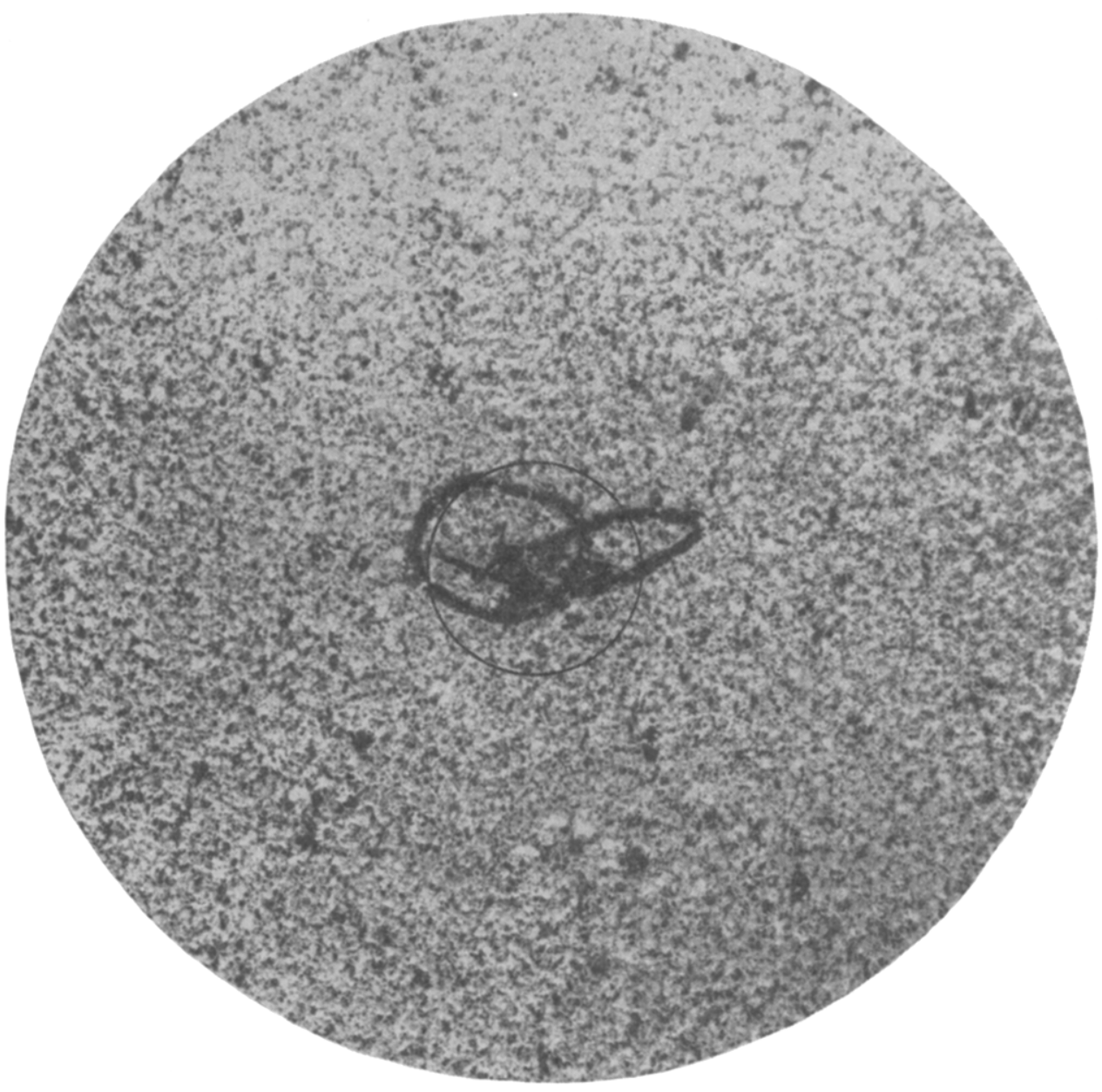

FIG. 8. Photograph of seismoscope record plate for the Hebgen Dam earthquake of 27 August 1959. Up on record is $\mathrm{N} 60^{\circ} \mathrm{W}$. Circle diameter $=2 \mathrm{~mm}$.

A special committee of the Earthquake Engineering Research Institute, with Professor C. Martin Duke of the University of California at Los Angeles as Chairman, prepared recommendations for detailed location of the individual instruments. In deciding on these locations, such factors as local geology, seismicity, population density, and proximity to existing accelerograph stations were considered. By 20 September 1960, some eighty of the available instruments had been installed in suitable locations, as indicated in fig. 5 .

Before installation, all seismoscopes were shop adjusted and tested by a standard 
procedure developed by Richard P. Maley, Geophysicist, of the Seismological Field Survey, U. S. Coast and Geodetic Survey (11). A standardized procedure was also developed by Maley for installation and checking. ${ }^{2}$ Shaking table tests indicated that if these standardized procedures were followed, the response of seismoscopes to identical forcing functions would seldom differ by more than $5 \%$.

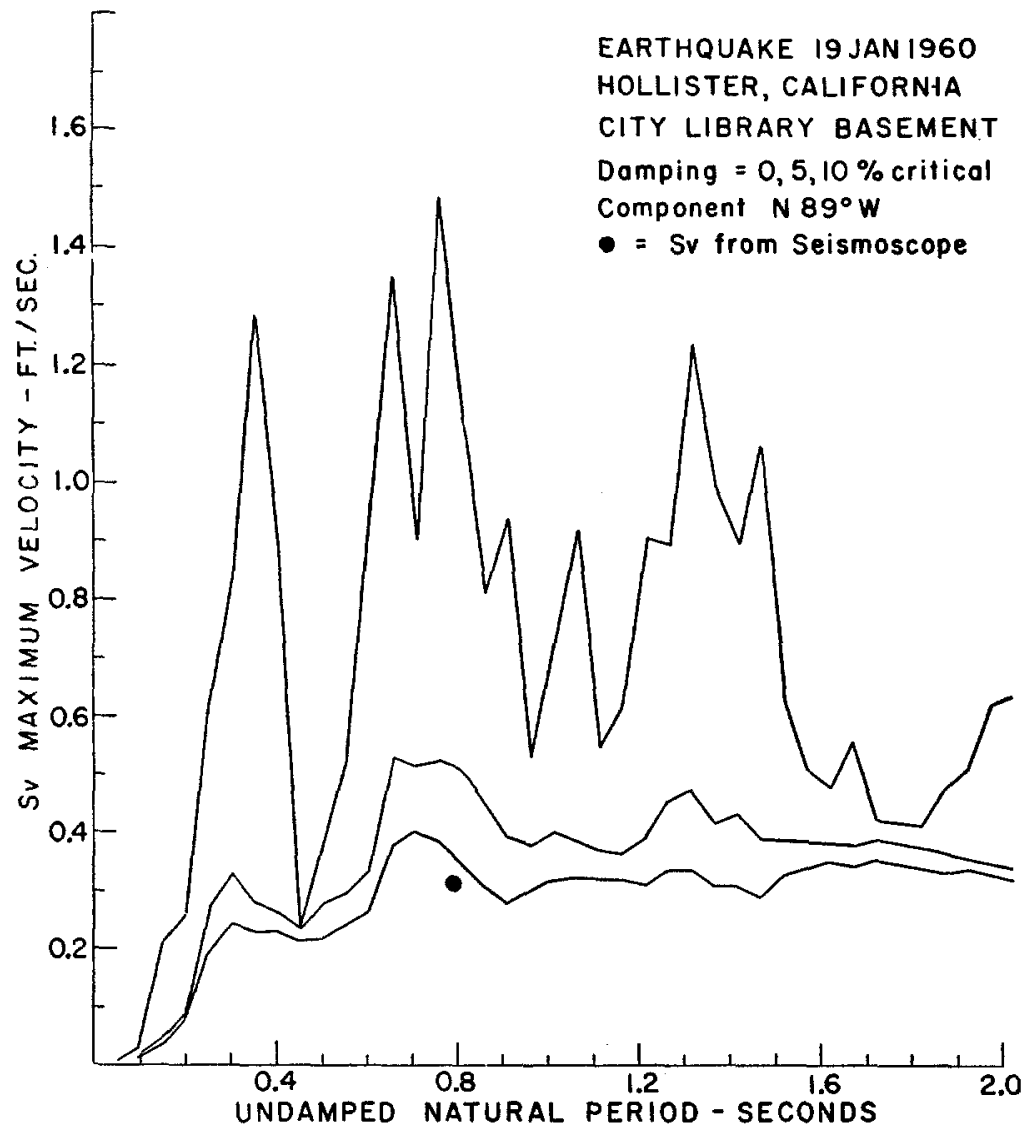

Fug. 9. Response spectrum for the Hollister earthquake of 19 January $1960, \mathrm{~N} 89^{\circ} \mathrm{W}$.

As of 20 September 1960, two earthquake records have been obtained from standard seismoscopes located immediately adjacent to recording accelerographs. It thus becomes possible to make a direct comparison of the seismoscope record with the response spectrum determined from the acceleration-time record for actual earthquakes under typical field conditions.

The ground acceleration records shown in fig. 6 were obtained from a temporary station installed in Montana after the major Hebgen Lake earthquake of 18 August 1959, and from the permanent station in the City Library at Hollister, California

\footnotetext{
${ }^{2}$ Copies of the report describing these standardized procedures may be obtained by writing to the U. S. Coast and Geodetic Survey, 407 New Mint Bldg., San Franciseo 2, California.
} 
of the earthquake of 19 January 1960. In fig. 7 are shown the relative velocity response spectrum curves for the two components at Hebgen Dam, as calculated by means of the Electric Analog Spectrum Analyzer by the U. S. Coast and Geodetic Survey. The single point marked on the same curve is the spectrum point as determined from the seismoscope record shown in fig. 8. Figures 9,10 , and 11 show simi-

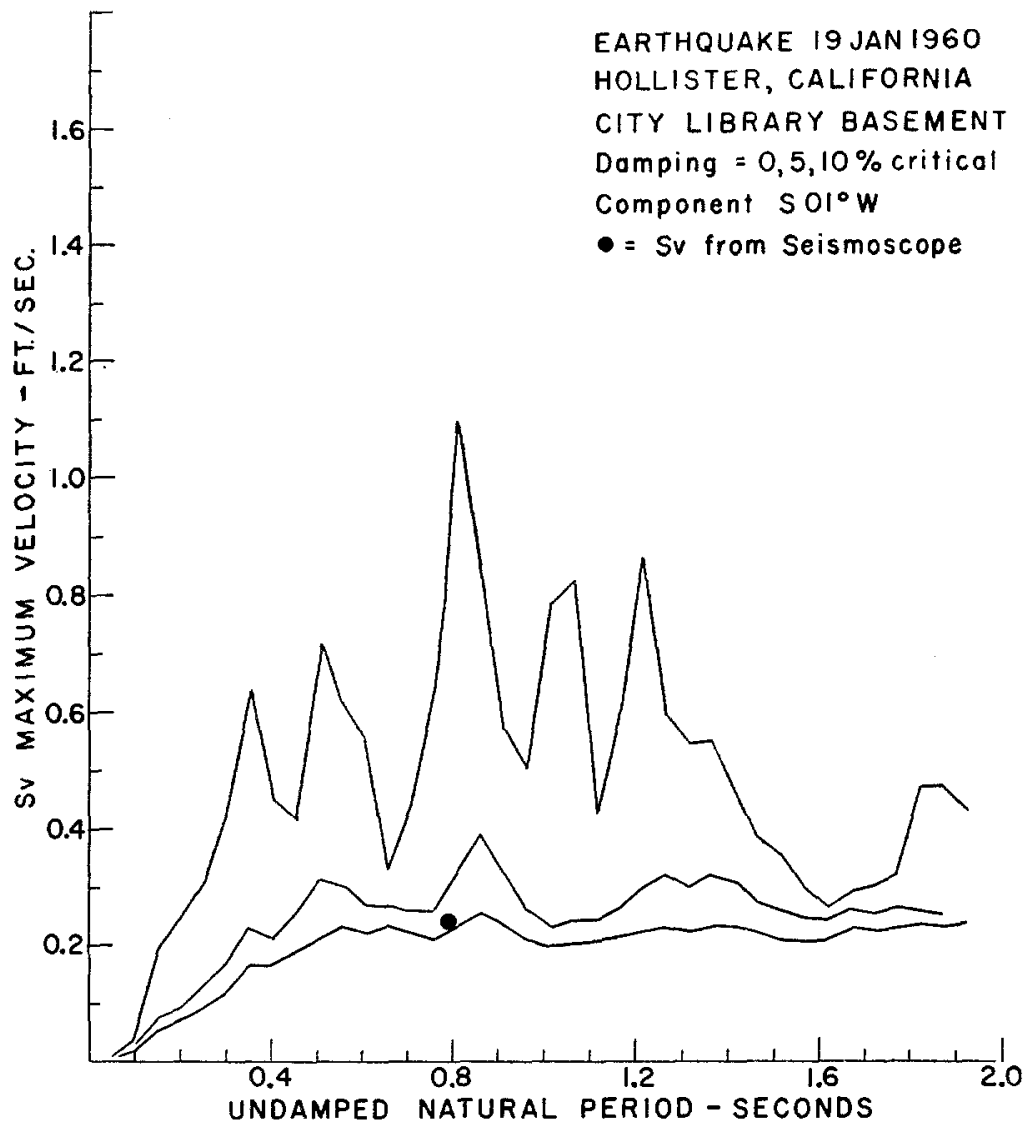

Fıg. 10. Response spectrum for the Hollister earthquake of 19 January $1960, \mathrm{~S} 01^{\circ} \mathrm{W}$.

lar comparisons for the Hollister shock. Pertinent data for the instruments and tests are summarized in table 1.

For these two earthquakes, the agreement between the seismoscope result and the complete spectrum analysis averages about $8 \%$. This agreement is consistent with the above estimates of the seismoscope accuracy, combined with the known accuracies of the accelerogram-spectrum analysis process. These initial results may be regarded as encouraging indications of the usefulness of the seismoscope, and of the satisfactory extent to which the original design criteria have been met.

\section{CONCLUSIONS}

Laboratory and field tests have established the usefulness of the U. S. Coast and Geodetic Survey seismoscope, and have indicated that the instrument can give, 


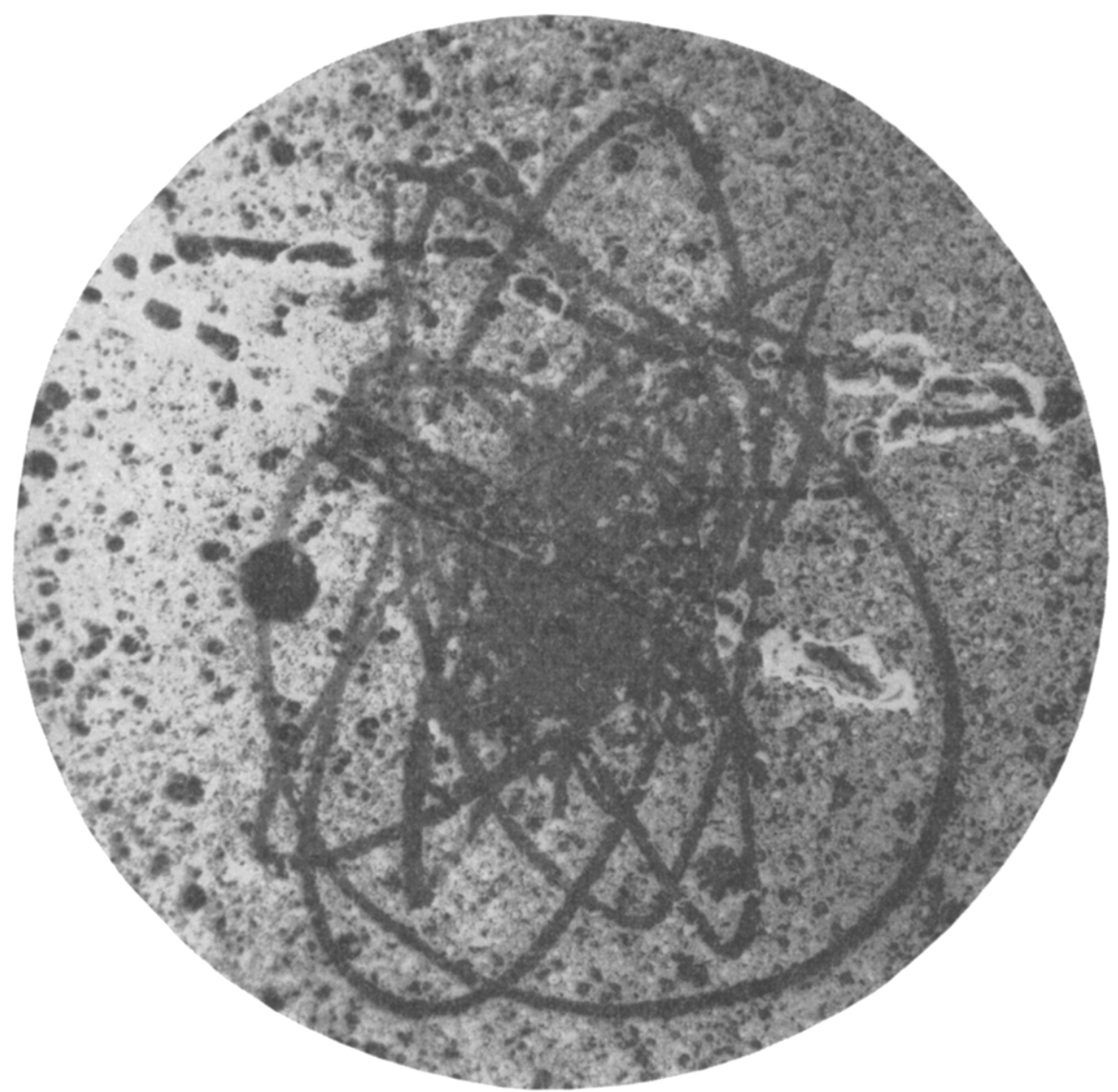

FIG. 11. Photograph of seismoscope record plate for the Hollister earthquake of 19 January 1960 . Up on record is west. Circle diameter $=2 \mathrm{~mm}$.

TABLE 1

Results Obtained from Seismoscopes Under Adtual Field Conditions

\begin{tabular}{|c|c|c|c|c|c|c|c|}
\hline & \multicolumn{6}{|c|}{ Seismoscope } & \multirow{2}{*}{$\begin{array}{l}S_{v} \text { Spectrum } \\
\text { Curve Value for } \\
T=0.79 \\
(\mathrm{ft} / \mathrm{sec})\end{array}$} \\
\hline & $\begin{array}{c}T \\
\text { Period } \\
\text { (sec) }\end{array}$ & $\begin{array}{c}n^{x} \\
\text { Damping } \\
\text { critical })\end{array}$ & $\begin{array}{c}S \\
\text { Sensitivity } \\
(\mathrm{cm} / \text { radian })\end{array}$ & $\underset{\text { Amplitude }}{A \text { Trace }}$ & $\begin{array}{l}\varphi=A / S \\
\text { (radians) }\end{array}$ & $\begin{array}{c}S v^{2} \\
\mathrm{ft} / \mathrm{sec}\end{array}$ & \\
\hline \multicolumn{8}{|c|}{ Hollister, California, earthquake of 19 January 1960} \\
\hline $\begin{array}{l}\mathrm{S} 01^{\circ} \mathrm{W} \\
\mathrm{N} 89^{\circ} \mathrm{W}\end{array}$ & 0.79 & $\begin{array}{l}12 \\
11.3\end{array}$ & $\begin{array}{l}6.00 \\
5.81\end{array}$ & $\begin{array}{l}0.327 \\
0.417\end{array}$ & $\begin{array}{l}0.0546 \\
0.0717\end{array}$ & $\begin{array}{l}0.24 \\
0.31\end{array}$ & $\begin{array}{l}0.22 \\
0.36\end{array}$ \\
\hline \multicolumn{8}{|c|}{ Hebgen Dam, Montana, earthquake of 27 August 1959} \\
\hline $\begin{array}{l}\mathrm{S} 30^{\circ} \mathrm{W} \\
\mathrm{N} 60^{\circ} \mathrm{W}\end{array}$ & 0.79 & $\begin{array}{l}18.7 \\
20\end{array}$ & $\begin{array}{l}6.18 \\
6.18\end{array}$ & $\begin{array}{l}0.140 \\
0.095\end{array}$ & $\begin{array}{l}0.0226 \\
0.0154\end{array}$ & $\begin{array}{l}0.125 \\
0.088\end{array}$ & $\begin{array}{l}0.134 \\
0.085\end{array}$ \\
\hline
\end{tabular}

${ }^{1}$ From damping curve for trace amplitude A.

${ }^{2} S_{v}=\frac{\varphi g T}{2 \pi} \sqrt{\frac{n}{10}}$. 
under typical conditions, a direct measurement of one point on the response spectrum with an overall accuracy of 5-10\%. It should always be kept in mind that the seismoscope is not intended to measure ground motion itself; it is not an accelerometer or a displacement meter, and no attempt should be made to derive acceleration or displacement information from the seismoscope records alone. The instrument can be considered as a dynamic model of a typical structure, and from the behavior of this dynamic model during an earthquake, calculations can be made which would indicate the behavior of various actual structures subjected to the same earthquake. Since it is this structural response rather than the ground motion which is often of primary importance to the engineer, the seismoscope should produce information of direct application to many problems of earthquake-resistant design.

The seismoscope should in no sense be considered as a replacement for a true time-recording accelerograph. Since some 40-50 seismoscopes can be obtained for the price of one accelerograph, however, it is evident that the simpler but more limited instrument should have important applications in extending the present networks of strong-motion earthquake instruments.

\section{Appendix-The Russian AIS-2 Seismometer}

It is interesting to note that an instrument which is in principle very similar to the U. S. Coast and Geodetic Survey seismoscope has recently been developed in Russia. The basic element in this Russian instrument, which has been described by A. G. Nazarov $(14,15)$, is a spherical pendulum consisting of a rod with an end mass. The upper end of the rod passes through a rubber bushing, which serves both as a universal joint and as a damping element. A scriber attached to the upper end of the pendulum records the horizontal motions of the pendulum on a smoked glass. The actual record is of a relatively small size, and is examined through a microscope for measurements.

Since there are no strong-motion earthquake response spectrum curves available for the Russian seismic areas to establish typical spectrum shapes, the instruments have been built with a number of pendulum elements having various natural periods. In this way an approximation to the complete spectrum curves can be obtained. One current model, the "AIS-2 Seismometer", contains horizontal elements having periods of $0.05,0.1,0.2,0.4,0.8$, and 1.2 seconds, and vertical elements having periods of $0.05,0.1$, and 0.2 seconds. The amount of damping is apparently of the order of $5-10 \%$ of critical, with the longer period elements having a smaller damping than the short period elements.

A number of these AIS-2 instruments have been installed in various seismic regions in Russia, and data for several small earthquakes and for blasts are included in the references. If the complete dynamic characteristics of the instrument were known, including the damping of each pendulum, it should be possible to directly compare the measurements made on the AIS-2 device and on the U. S. Coast and Geodetic Survey seismoscope.

\section{ACKNOWLEDGMENTS}

The design and construction of the prototype seismoscope was carried out by the U. S. Coast and Geodetic Survey under the direction of Elliot B. Roberts, Chief, 
Division of Geophysics. Numerous contributions were made by various members of the Seismological Field Survey Staff, including Richard P. Maley, John Hershberger, and Charles F. Knudson. C. Martin Duke and David J. Leeds of the University of California at Los Angeles made the required studies on seismoscope location. Many useful suggestions for production of the field model were made by J. J. Wilmot of Wilmot Engraving and Instrument Company. Wilfred D. Iwan of the Division of Engineering, California Institute of Technology, conducted the laboratory tests of the field model. Thanks are expressed to the National Science Foundation for a grant through the Engineering Sciences Division, which was administered for the California Institute of Technology by G. W. Housner and D. E. Hudson.

\section{REFERENCES}

1. Galitzin, B., "Uber Eine Dynamische Skala zer Schatzung von Makroseismischen Bewegungen", St. Petersburg, 1913, Review by H. O. Wood in Bull. Seis. Soc. Am., vol. 3, no. 2,1913 .

2. Kirkpatrick, P., "Seismic Measurements by the Overthrow of Columns", Bull. Seis. Soc. Am., vol. 17, no. 2, 1927.

3. Edwards, A. T., and Northwood, T. D., Experimental Blasting Studies on Structures, Hydro-Electric Power Commission and the National Research Council, Canada, 1959.

4. Suyehiro, K., "A Seismic Vibration Analyzer and the Records Obtained Therewith", Bull. Earthq. Res. Inst., Tokyo, vol. 1, 1926.

5. Suyehiro, K., "Engineering Seismology-Notes on American Lectures", Proc. A.S.C.E., vol. 58, no. 4, 1932.

6. Ulrich, F. P., "Progress Report for 1939 of the Seismological Field Survey of the U.S. Coast and Geodetic Survey", Bull. Seis. Soc. Am., vol. 31, no. 2, 1941.

7. Hudson, D. E., and Housner, G. W., "An Analysis of Strong-Motion Accelerometer Data from the San Francisco Earthquake of March 22, 1957", Bull. Seis. Soc. Am., vol. 48, no. 3,1958 .

8. Hudson, D. E., The Wilmot Survey Type Strong-Motion Earthquake Recorder, Earthquake Engineering Research Laboratory, California Institute of Technology, September 1958.

9. Housner, G. W., Martel, R. R., and Alford, J. L., "Spectrum Analysis of Strong-Motion Earthquakes", Bull. Seis. Soc. Am., vol. 43, no. 2, 1953.

10. Hudson, D. E., "Response Spectrum Techniques in Engineering Seismology", Proc. World Conf. on Earthquake Eng., Earthquake Engineering Research Institute and the University of California, Berkeley, 1956.

11. Maley, R. P., Standard Procedure for Adjustment and Installation of U.S. Coast and Geodetic Survey Seismoscopes, Report to Seismological Field Survey, Coast and Geodetic Survey, 1960 .

12. Kanai, K., and Sezawa, K., "On the Problem of Instabilities of Higher Orders in a Seismometer, I”, Bull. Earthq. Res. Inst., vol. XVIII, No. 4, 1940.

13. Hudson, D. E., “Ground Motion Measurements in Earthquake Engineering”, Earthquake Engineering, Seminar Series No. 1, University of Roorkee, Roorkee, U.P. India, 1959.

14. Nazarov, A. G., The Method of Engineering Analysis of Seismic Forces, Academy of Sciences of the Armenian SSR, Yerevan, 1959 (in Russian).

15. Nazarov, A. G., Karapetian, B. K., and Shahinian, S. A., "The Method of Direct Determination of Reduced Spectra of Seismic Accelerations", Proc. Second World Conf. on Earthquake Eng., Tokyo, 1960, (in English).

W. K. C.

Seismological Field Survey, U. S. Coast and Geodetic Survey, San Francisco, California.
D. E. H.

Division of Engineming,

California Institute of Technology, Pasadena, Califorinta. 